Goldschmidt 2021 Abstract

https://doi.org/10.7185/gold2021.7755

\section{Investigating the Eruption Histories of Apollo 17 Basalts Using 3D Data}

\author{
ZOE E WILBUR ${ }^{1}$, JESSICA J BARNES ${ }^{1}$, SCOTT A \\ ECKLEY $^{2,3}$ AND RYAN A ZEIGLER ${ }^{2}$ \\ ${ }^{1}$ University of Arizona \\ ${ }^{2}$ NASA Johnson Space Center \\ ${ }^{3}$ University of Texas, Austin \\ Presenting Author: zewilbur@email.arizona.edu
}

Volatile elements and halogens affect the crucial rheologic properties of minerals and melts, thereby influencing eruption processes. Previous studies show that despite being volatile depleted, lunar basalts contain measurable amounts of magmatic volatiles [e.g. 1,2]. Many lunar basaltic samples contain void spaces, termed vesicles and vugs, which are important testaments to gas-rich volcanic activity that occurred on the Moon. The combination of direct volatile chemistry with textural analyses, including the abundances and fabric of voids, can yield powerful insights into the volcanic history of lunar basalts. Moreover, when such data is coupled with eruption ages, a comprehensive picture of their magmatic origin and post-magmatic evolution can be revealed.

This work utilizes three Apollo 17 basalts collected from a boulder at Station 1A at the rim of Steno Crater: 71035, 71037, and 71055 . We scan and visualize these basalts using X-ray computed tomography (XCT), an invaluable tool used to nondestructively analyze the interior of a sample. The processing of XCT data in Blob3D and Quant3D software allows us to quantify $3 \mathrm{D}$ modal mineralogy, measure void dimensions and abundances, and constrain vesicle fabrics and morphologies in these basalts.

Preliminary examination of the XCT results have allowed for the identification of 3D modal mineralogy and vesicles in differing sizes and fabrics (Fig. 1). The lunar basalts show a wide range of textures indicative of their cooling histories. To quantify these textures and define cooling histories, we will compare 3D CSD measurements to 2D measurements from our other work. We hope to elucidate if the samples originate from the same flow, and if they can be related stratigraphically. This work is critical to developing a complete picture of the cooling, volatile loss, and volcanic histories of these lunar basalts.

Figure 1. 3D rendered XCT scans of 71035,36 and 71055,10. Vesicles are purple, and the sample matrix is opaque grey. Vesicles with flat surfaces are in contact with the exterior of the sample. Despite originating from the same boulder, the vesicle textures between the two samples differ.

[1] Haskin and Warren (1991) Lunar sourcebook, 4(4), pp.357-474.

[2] McCubbin et al. (2015) American Mineralogist, 100(8-9), pp.1668-1707.

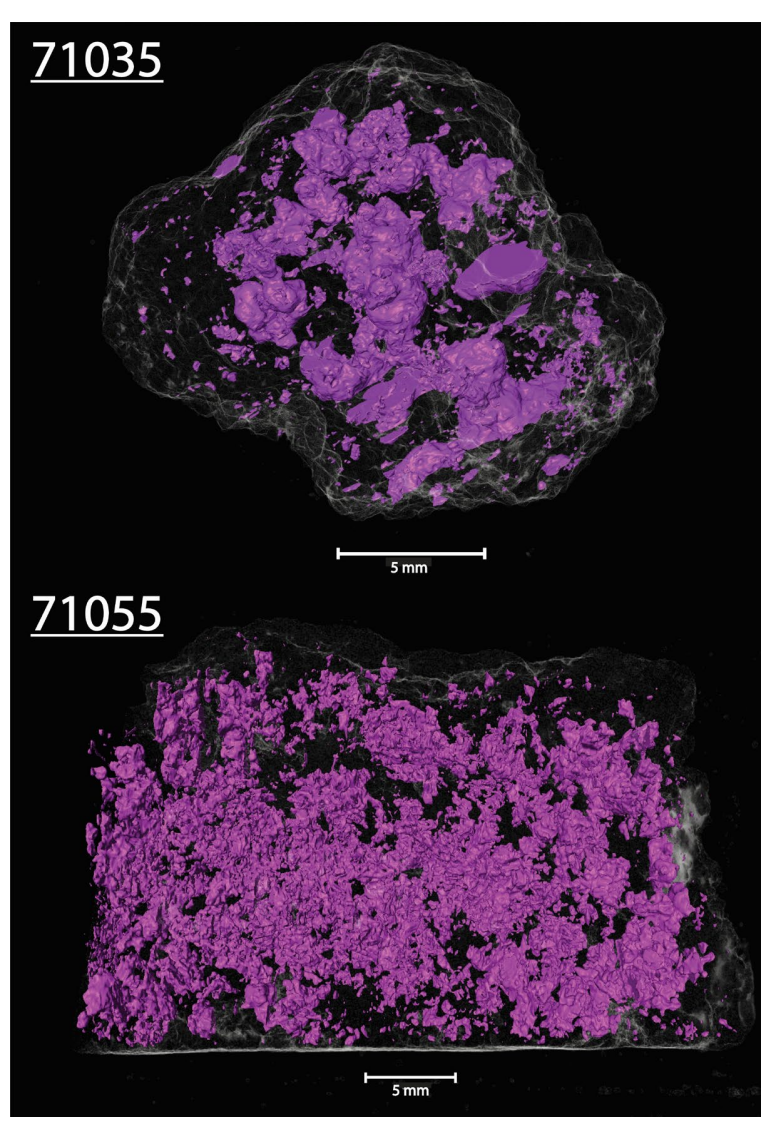

